\title{
Proceeding
}

9th INSHS International Christmas Sport Scientific Conference, 4-6 December 2014. International Network of Sport and Health

Science. Szombathely, Hungary

\section{Skin temperature changes of muscle regions in training swimmers}

\author{
SILVIE RYBÁŘOVÁ $\triangle$, JAN NOVOTNÝ \\ Faculty of Sport Studies, Masaryk University, Brno, Czech Republic
}

\begin{abstract}
Rybárová, S., \& Novotný, J. (2015). Skin temperature changes of muscle regions in training swimmers. J. Hum. Sport Exerc., 9(Proc1), pp.S192-S197. Purpose: Our aim was to detect changes in infrared radiation, overloaded structures of the musculoskeletal system at the main part of the shoulder girdle and upper body with the help of elite swimmers of Kometa Brno. Methods: First measurement was done before training and second 15 minutes after training in water in the swimming pool. The group consisted of seven Czech national swimmers. Athletes participated in testing during six months. Every measurement contains four positions. Front and back side, right and left side. Every athlete went through 13 measurements. We directed infrared thermograph camera FlukeTiR at 10 muscular groups that are most used in swimming. Besides we have form about training with kilometres, other exercise out of water, competitions, illness and be absent at training and other pain muscles, ligaments etc. Results: We have analysed all temperatures only of one swimmer. Here was significant increased temperature after swimming only in deltoideus anterior at right side (from $33.4 \pm 1.02^{\circ} \mathrm{C}$ to $34.0 \pm 0.69^{\circ} \mathrm{C}$ ). The other temperature was significant decreased: muscles groups of pectoralis major and minor (right side from $33.6 \pm 0.92$ to $33.1 \pm 0.61^{\circ} \mathrm{C}$; left side from $33.8 \pm 0.82$ to $33.1 \pm 0.69^{\circ} \mathrm{C}$ ), latissimus dorsi and erector spinae - pars lumbalis at both sides together. Conclusion: Five of twenty muscle regions have notable tendencies of increased temperatures, including a front part of deltoideus at right side which is very active by spreading arm forward and beginning of swimming stroke. In nine areas, including the main agonist for swimmers movement forward - triceps brachii, we found out only no significant lowering of temperatures. That was caused by cooling of the swimmer in the water. We have next six swimmers to analysis. Key words: SWIMMING, INFRARED THERMOGRAPHY, MUSCULAR WORK.
\end{abstract}

\footnotetext{
Corresponding author. Žerotínovo nám. 617/9, 60177 Brno, República Checa

E-mail: 160531@mail.muni.cz

9th INSHS International Christmas Sport Scientific Conference, 4-6 December 2014. International Network of Sport and

Health Science. Szombathely, Hungary.

JOURNAL OF HUMAN SPORT \& EXERCISE ISSN 1988-5202

(c) Faculty of Education. University of Alicante

doi:10.14198/jhse.2015.10.Proc1.05
} 


\section{INTRODUCTION}

A very good method to measure individual muscle activity is electromyography. This method provides information on electric muscular activity which is prior to metabolic activity itself. In recent years, results of electromyographical studies have been published on muscular activity during swimming (Conceição et al., 2013; Lauer et al., 2013).

Scientific articles on thermal changes as a result of swimming in water are rare. (Wade \& Veghte, 1977) observed four professional swimmers after a 500-meter free style swim in water of $23.5^{\circ} \mathrm{C}$. (Zaidi, Taiar, Fohanno \& Polidori, 2007) described the temperature changes in one swimmer. The swimmer used in turns all four swimming styles. Each for 1 minute and there were 10-minute breaks between them. They defined the temperature of large body segments and they did not evaluate the areas corresponding to particular muscles. For example, dorsal arm included dorsal deltoid muscles and triceps.

We want to help with solution measuring and show metabolic activities in progress and muscles groups on swimming. For measuring our dates we have used infrared thermograpy. Our aim was to detect changes in infrared radiation, overloaded structures of the musculoskeletal system at the main part of the shoulder girdle and upper body with the help of elite swimmers of Kometa Brno.

Than find out if there is some new thermally interesting areas before and after training in local area or hole muscle.

Purpose is to find if thermograph can find or prevent injury of movement musculoskeletal system. Healthy is key to the top athlets.

\section{MATERIAL AND METHODS}

\section{Athletes group}

Over group consisted of seven Czech national swimmers of Kometa Brno. The group are 5 men and 2 women, from 20 to 34 years old. They had 11 weeks of training in water and 3 units of dry land. Training in water is around $50-70 \mathrm{~km}$ per week. It is around $2000 \mathrm{~km}$ per year. They are specializing in freestyle for long $(5-25 \mathrm{~km})$ and short distance $(50 \mathrm{~m}, 100 \mathrm{~m})$.

We chose one swimmer for a complete analysis of measurement. He is 24 years old, $183 \mathrm{~cm}$ high and 76 $\mathrm{kg}$ weight. His main style is free-style in open water. Mains discipline is $5 \mathrm{~km}$ and $10 \mathrm{k} \mathrm{m}$. He is Czech national swimmer and he was at European and World championships. He had this year $2200 \mathrm{~km}$ per year. He stared with swimming 16 years ago.

\section{Measurement}

1. Measurement was done before training.

2. 15 minutes after training

Training was in water in the swimming pool. There was temperature of water $27^{\circ} \mathrm{C}$. One unit was 2 hour long and measuring was done regulary in training since 6 to 8 in the morning. Before first measuring was the body 15 minutes nude a after training the swimmer has use the towel and sit for 15 minutes in the pool. Athletes participated in monitoring during six months. Measurements were made from January to June. Every athlete went through 13 measurements. We have 104 pictures of one swimmer. Every measurement contains four positions. Front and back side, right and left side. 


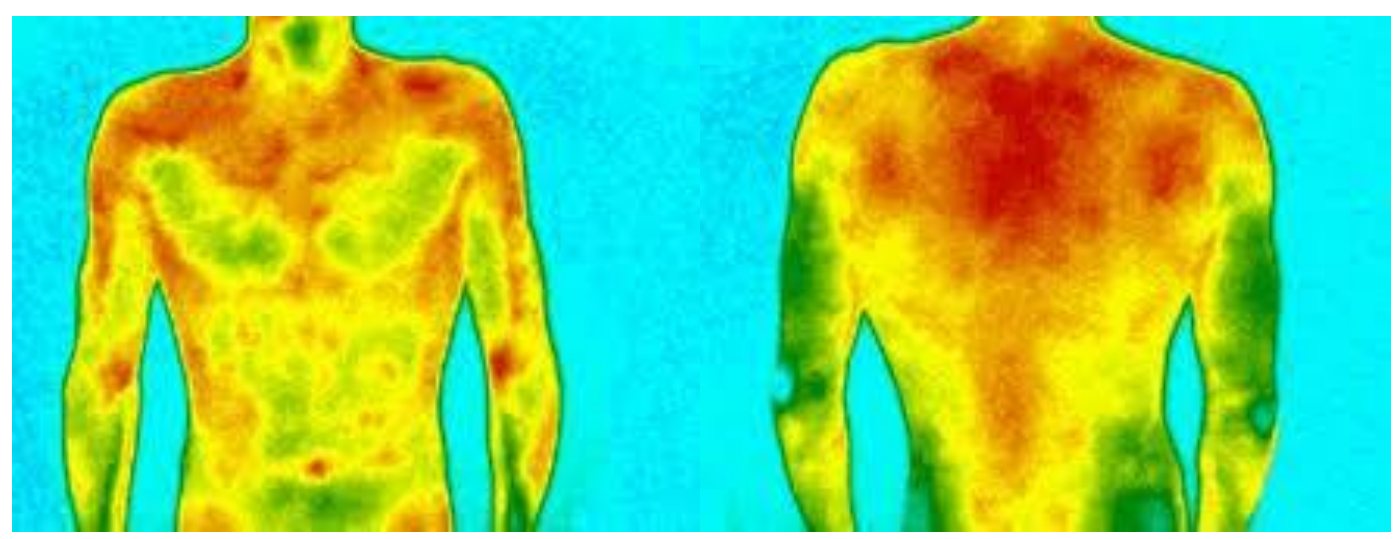

Figure 1. Thermograms of front side and back side

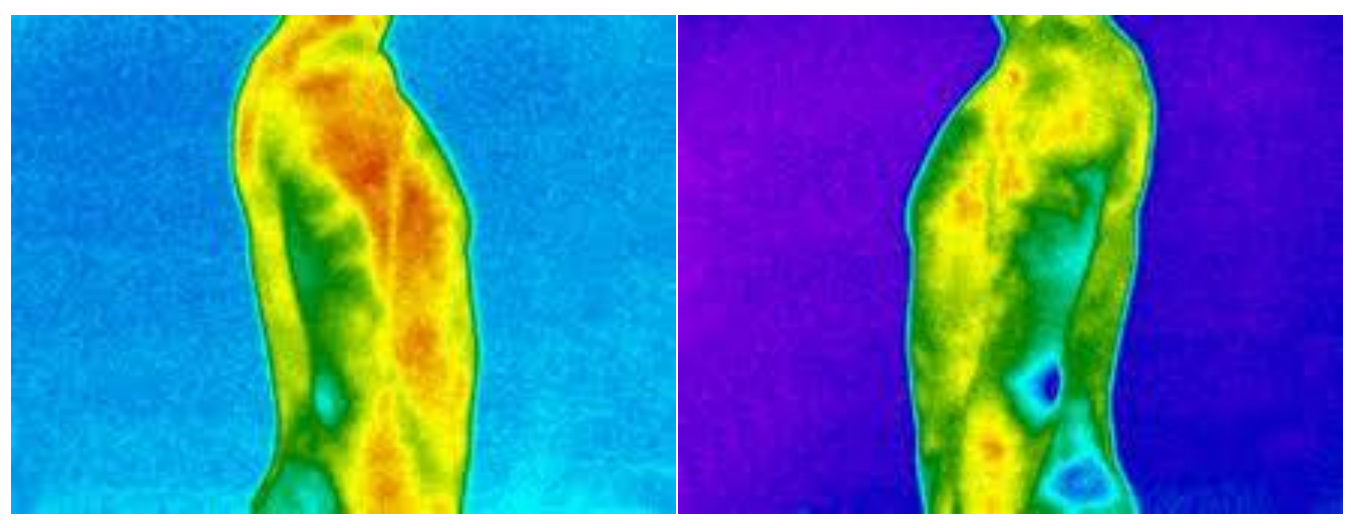

Figure 2. Thermograms of right side and left side

We directed infrared thermograph camera FlukeTiR at 10 muscular groups that are most used in swimming.

Camera is hand-held, infrared spectral band $7.5 \mu \mathrm{m}$ to $14 \mu \mathrm{m}$ portable, $23 \times 17^{\circ} \mathrm{C}$ lens, manual focus, sensitivity of $0.1^{\circ} \mathrm{C}, \mathrm{LCD}$ display with a resolution of $480 \times 640$ pixels. At the display there was the temperature distribution of body surface.

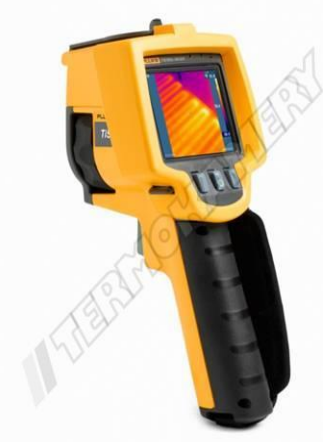

Figure 3. Camera FlukeTiR 
We measured the skin infrared radiation of selected 10 muscle groups of the upper body for swimmers that are most involved in the movement in the water.

Table 1. Selected regions of interest (ROI)

\begin{tabular}{cc}
\hline $\mathrm{ROI}$ & Muscles, their parts or groups \\
\hline $\mathrm{Da}$ & m. deltoideus - pars anterior \\
$\mathrm{Dp}$ & m. deltoideus - pars posteriori \\
$\mathrm{Dl}$ & m. deltoideus - pars lateralit \\
$\mathrm{Bb}$ & $\mathrm{m}$. biceps brachii \\
$\mathrm{Tb}$ & m. triceps brachii \\
$\mathrm{Ts}$ & m. trapezius - pars superior \\
$\mathrm{P}$ & m. pectoralis major et minor \\
$\mathrm{R}-\mathrm{Ti}$ & m. rhomboideus major et minor, and m. trapezius - pars inferior \\
$\mathrm{Ld}$ & m. latissimus dorsi \\
$\mathrm{Esl}$ & m. erector spinae - pars lumbalis \\
\hline
\end{tabular}

\section{RESULTS OF SELECTED SWIMMER}

Table 2. Temperatures of selected regions

\begin{tabular}{|c|c|c|c|c|c|c|c|c|}
\hline \multirow[b]{3}{*}{ ROI } & \multicolumn{4}{|c|}{ Left side } & \multicolumn{4}{|c|}{ Right side } \\
\hline & \multicolumn{2}{|c|}{ Before } & \multicolumn{2}{|c|}{ After } & \multicolumn{2}{|c|}{ Before } & \multicolumn{2}{|c|}{ after } \\
\hline & $X$ & $S$ & $X$ & $S$ & $X$ & $S$ & $\bar{X}$ & $S$ \\
\hline $\mathrm{Da}$ & 33.6 & 0.93 & 34.0 & 0.56 & 33.4 & 1.02 & 34.0 & 0.69 \\
\hline $\mathrm{Dp}$ & 33.8 & 1.05 & 34.2 & 0.62 & 33.9 & 0.96 & 34.1 & 0.70 \\
\hline $\mathrm{DI}$ & 33.8 & 0.78 & 33.5 & 0.79 & 33.9 & 0.77 & 33.6 & 0.77 \\
\hline $\mathrm{Bb}$ & 33.7 & 0.92 & 33.5 & 0.61 & 33.6 & 1.00 & 33.2 & 0.68 \\
\hline $\mathrm{Tb}$ & 32.7 & 0.90 & 32.6 & 0.65 & 32.7 & 1.03 & 32.8 & 0.65 \\
\hline Ts & 34.2 & 0.73 & 34.1 & 0.62 & 34.4 & 0.74 & 34.3 & 0.62 \\
\hline$P$ & 33.8 & 0.82 & 33.1 & 0.69 & 33.6 & 0.92 & 33.1 & 0.61 \\
\hline R-Ti & 34.3 & 0.77 & 34.1 & 0.84 & 34.4 & 0.73 & 33.9 & 0.77 \\
\hline $\mathrm{Ld}$ & 33.9 & 0.61 & 32.9 & 0.70 & 34.2 & 0.52 & 33.1 & 0.43 \\
\hline Esl & 34.5 & 0.49 & 32.7 & 0.86 & 34.5 & 0.47 & 32.8 & 0.98 \\
\hline
\end{tabular}

Key: x-everage; s-the standard deviation 
We have analysed all temperatures only of one swimmer. Here was significant increased temperature after swimming only in deltoideus anterior at right side (from $33.4 \pm 1.02^{\circ} \mathrm{C}$ to $34.0 \pm 0.69^{\circ} \mathrm{C}$ ) (Fig. 4.). The other temperature was significant decreased: muscles groups of pectoralis major and minor (right side from 33.6 \pm 0.92 to $33.1 \pm 0.61^{\circ} \mathrm{C}$; left side from $33.8 \pm 0.82$ to $33.1 \pm 0.69^{\circ} \mathrm{C}$ ) (Fig. 5.), latissimus dorsi and erector spinae - pars lumbalis at both sides together.

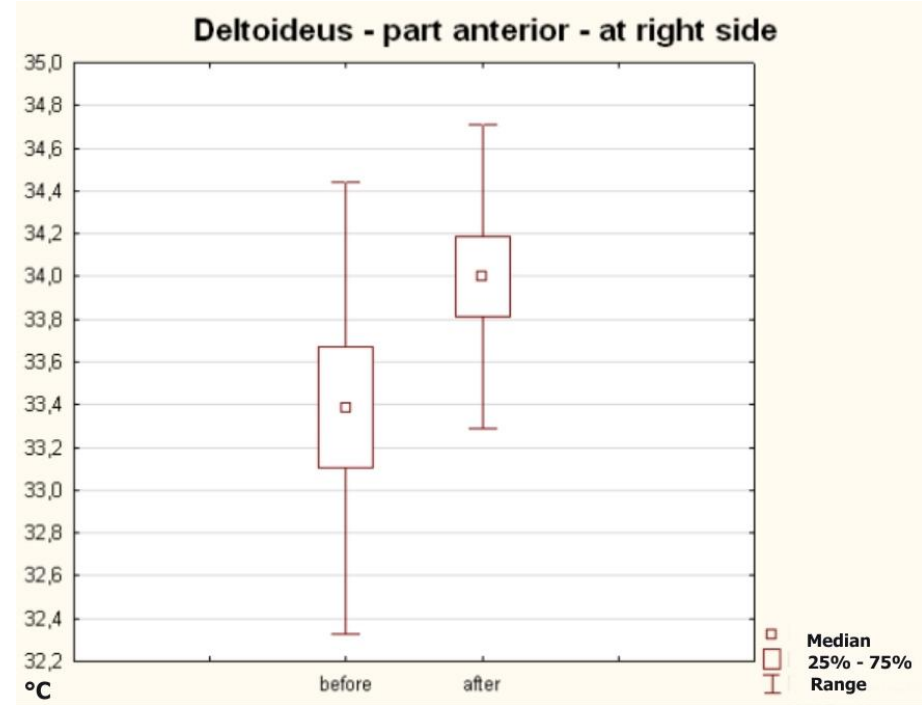

Figure 4. Temperature before and after swimming in region of deltoideus anterior at right side

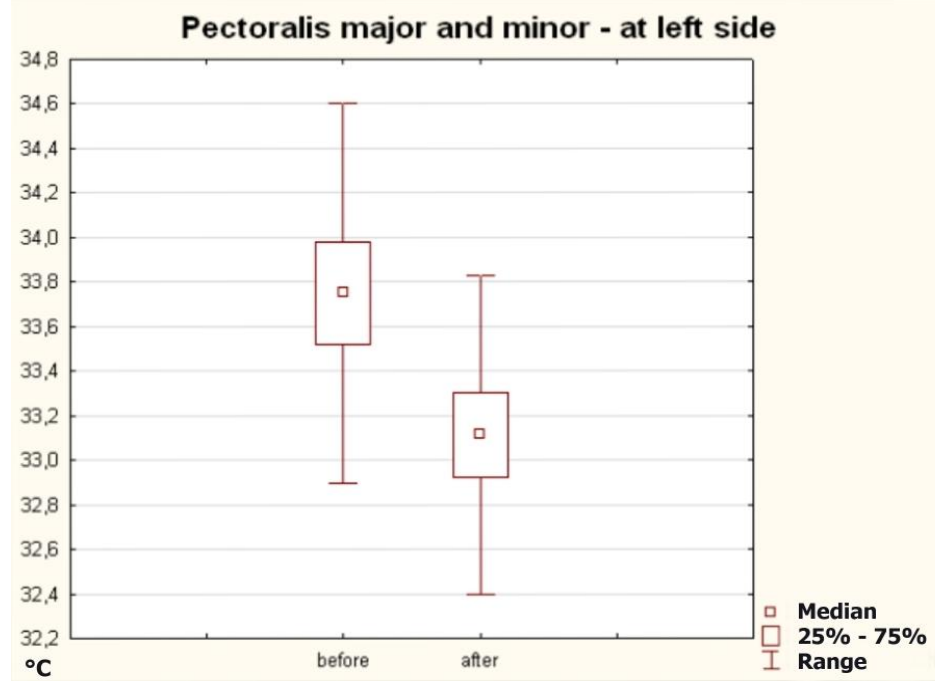

Figure 5. Temperature before and after swimming in region of pectoralis major and minor at left side

\section{DISCUSSION}

Our swimmer has only warming on his muscles deltoidus. He is right handed, and it is visible on his hand work in the water. Stroke is stronger and the hand is not so much lose. You can see it on his technique. Deltoideus muscle is really active in use under water as up the water stroke. 
We haven't found any change of body temperature during hole measuring, the swimmer have no problems or pain.

Other muscular parts and groups have degrees of temperature. That is because cold water and air is colder than the body temperature. We had the other measurement, but it was so early after training and at skin was too much water. The measurement has been canceled. It is not applicable.

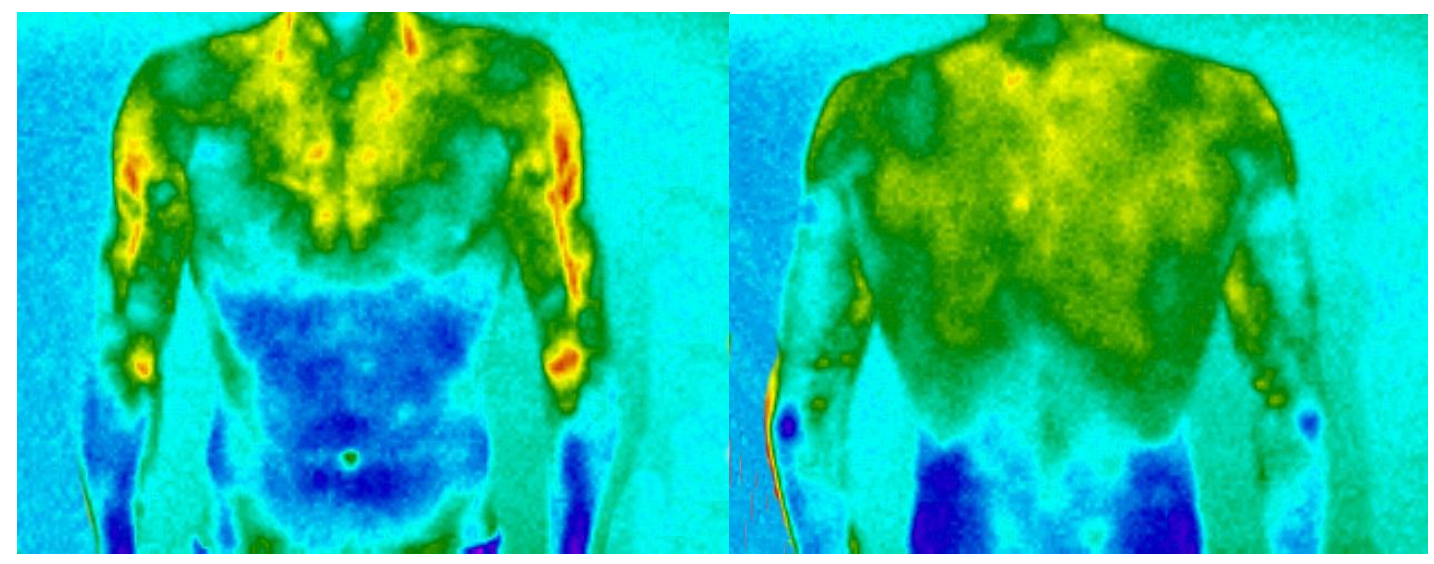

Figure 6. Skin with water at front and back side after training

\section{CONCLUSIONS}

We got results by measuring only one person. Five of twenty muscle regions have notable tendencies of increased temperatures, including a front part of deltoideus at right side which is very active by spreading arm forward and beginning of swimming stroke. In nine areas of main agonist swimmers movement forward included - triceps brachii, we have find out only no significant lowering temperatures. That because cooling of the swimmer in the water. We haven't found any source or areas showing injury or damage muscle system. We need to analyze more swimmers for better results. We have next six swimmers to analysis.

\section{REFERENCES}

1. Conceição, A., Silva, A., Barbosa, T.M., \& Louro, H. (2013). Observation and technical characterization in swimming: $200 \mathrm{~m}$ breaststroke. Revista Brasileira de Medicina do Esporte, 19(1), pp.56-61.

2. Lauer, J., Figueiredo, P., Vilas-Boas, J.P., Fernandes, R.J., \& Rouard, A.H. (2013). Phasedepence of elbow muscle coactivation in front crawl swimming. Journal of Electromyography \& Kinesiology, 23(4), pp.820-826.

3. Wade, C.E., \& Veghte, J.H. (1977). Thermographic evaluation of the relative heat loss by area in man after swimming. Aviation, Space and Environmental Medicine, 48, pp.16-18.

4. Zaidi, H., Taiar, R., Fohanno, S., \& Polidori, G. (2007). The influence of swimming type on the skintemperature maps of a competive swimmer from infrared thermography. Acta Bioenineering and Biomechanics, 9(1), pp.47-51. 